\title{
Concepts, Meanings and Truth: First Nature, Second Nature and Hard Work
}

\author{
PAUL M. PIETROSKI
}

\begin{abstract}
I argue that linguistic meanings are instructions to build monadic concepts that lie between lexicalizable concepts and truth-evaluable judgments. In acquiring words, humans use concepts of various adicities to introduce concepts that can be fetched and systematically combined via certain conjunctive operations, which require monadic inputs. These concepts do not have Tarskian satisfaction conditions. But they provide bases for refinements and elaborations that can yield truth-evaluable judgments. Constructing mental sentences that are true or false requires cognitive work, not just an exercise of basic linguistic capacities.
\end{abstract}

How are the concepts that we humans deploy in thought related to the meanings of expressions that we use in speech? How are these concepts and meanings related to judgments that are true or false? Does distinctively human thought require special atomic concepts, special ways of combining concepts, or both? In this paper, I offer some tentative answers that cohere, drawing on Chomsky $(1977,1986,1995$, 2000) and many others.

The leading idea is that in the course of language acquisition, humans use available concepts to introduce formally new concepts that can be fetched via lexical items and combined via certain operations that are invoked by the human faculty of language (HFL). On this view, words do not merely label concepts in accord with grammatical principles. Acquiring words is a process in which prior concepts - of diverse and perhaps incommensurate sorts - are used to make concepts that exhibit the format required by the composition operations that correspond to phrasal syntax. More specifically, I claim that these operations are fundamentally conjunctive, and that they require monadic inputs. For example, if 'give' lexicalizes a relational concept, a corresponding monadic concept (of events) must be introduced for purposes of fetching and conjoining with others. In which case, human linguistic competence is no mere capacity to generate expressions whose elements label the concepts we lexicalize. To have a language like English is to have a cognitive tool that lets one reanalyze independently available thoughts as thoughts whose main constituents are systematically recombinable monadic conjuncts. This can be useful, even without interpersonal communication, since conjunction of monadic concepts is a simple operation with logical consequences that are easy to track.

For helpful comments and discussion, my thanks to: Cedric Boeckx, Susan Dwyer, Valentine Hacquard, Norbert Hornstein, Terje Lohndal, Jim McGilvray, Barry Smith, Alexander Williams, and three referees.

Address for correspondence: Department of Linguistics, University of Maryland, College Park, MD 20742, USA.

Email: pietro@umd.edu 
This way of thinking about languages, as tools for reformatting representations in computationally useful ways, was central to Frege's $(1879,1884)$ conception of logic. But Frege was mainly concerned with invented languages and the kind of abstraction required for inductive proofs in arithmetic. So as reviewed below, combining expressions in his Begriffsschrift signifies saturation of one concept by another, allowing for higher-order polyadic concepts. According to many current theories, natural human languages are similar with regard to semantic composition. But as we'll see, this hypothesis faces difficulties. My alternative suggestion is that while children naturally acquire languages that support the introduction of concepts that exhibit a psychologically useful format, the new concepts are monadic and logically boring.

The main background assumption, discussed in section one, is that HFL lets humans acquire biologically implemented procedures (I-languages, in Chomsky's sense) that generate pronounceable instructions to build mental representations. Section two reviews some facts that motivate my version of the leading idea: the concepts introduced by lexicalization (I-concepts) are monadic, and the relevant composition operations are conjunctive, while the concepts we lexicalize (L-concepts) are more diverse. This hypothesis has implications, explored in section three, for the questions posed at the outset. My conclusion is that HFL generates expressions that direct the construction of systematically combinable concepts that exhibit distinctive formal properties, and that having such concepts makes it possible for us to form truth-evaluable judgments given some additional cognitive talents. But our words are not true of things we talk about. ${ }^{1}$

\section{Assumptions and Advertisements}

In this section, I illustrate the proposal within a more general theoretical framework.

\subsection{Introducing Concepts}

Following Fodor $(1975,1986,2003)$ and others, I take concepts to be mental symbols that can be combined to form complex symbols whose representational properties are compositionally determined. More specifically, concepts exhibit various adicities (or valences) that determine how they can be combined. In terms of Frege's (1892) metaphor, complex concepts are formed by combining an unsaturated concept with one or more saturating concepts.

I assume that humans and many other animals have singular concepts, like Brutus and Caesar, that let us think about individuals who can be tracked

1 Cp. Bach, 1994; Carston, 2002, 2008; Recanati, 2004. Chomsky (1977, 2000) notes the compatibility of his project in linguistics with certain themes concerning the use of language running though Wittgenstein (1953), Austin (1962), and Strawson (1950); see also McGilvray, 1998, 1999; Pietroski, 2005a and Stainton, 2006. Jackendoff (1990, 2002) presses similar considerations in a different way. 
through space and time. Singular concepts can saturate concepts like ARRIVED(x) and SAW (X, Y) — used to classify and relate represented individuals - to form 'complete' sentential representations like arrived(Brutus) and SAw(Brutus, Caesar). Conversely, abstracting away from the saturaters in a completed concept leaves a mental 'sentence frame' that can be described as an unsaturated concept whose adicity is the number of saturatable positions: $\operatorname{ARRIVED}(\mathrm{X})$ is monadic, SAW $(\mathrm{X}, \mathrm{Y})$ is dyadic, $\operatorname{GrVE}(\mathrm{X}, \mathrm{Y}, \mathrm{z})$ is triadic, etc. There is surely a limit to the adicities exhibited by natural concepts. But tetradic concepts may be common; think about squares, or the difference between selling and giving. And we seem to have higher-order numeric/set-theoretic/quantificational concepts that can be saturated by monadic concepts, as in THREe/INCLUde/MOst $[\operatorname{BrOwN}(\mathrm{x}), \operatorname{COW}(\mathrm{x})]$. In short, concepts compose and exhibit a limited hierarchy of types.

One can take these points as terminological, governing my use of 'concept', since my claim is not that all representations exhibit syntax in this sense. ${ }^{2}$ But while each concept is combinable with some others, an animal's concepts need not be totally integrated in the sense that any two subsentential concepts can be constituents of a third. A mind might include multiple Languages of Thought, each associated with certain modules but not others, and thus include various families of concepts with features that preclude fully systematic intermingling. Imagine an animal with unsaturated concepts of different sorts - perhaps a concept of sounds $\mathrm{S}(\mathrm{x})$, a causal concept $\mathrm{C}(\alpha, \beta)$, a temporal concept $\mathrm{T}(\mathrm{I}, 2,3)$, and a concept of actions $\mathrm{A}(\zeta)$ such that: each has a restricted range of potential saturaters from its own family; but the animal cannot form variable neutral concepts like $[\mathrm{S}(\mathrm{v})$ \& $\mathrm{A}(\mathrm{v}$ ') \& C(v', v') \& $\left.T\left(v^{\prime \prime}, v^{\prime}, v^{\prime}\right)\right]$, whose adicities may exceed that of any primitive constituent. I readily grant that many human concepts are as combinable as their lexical counterparts; cp. Evans, 1982; Fodor and Pylyshyn, 1998. But if some of our concepts are like linguistic expressions, in that any two can be constituents of a third, one wants to know how and when these concepts emerged. Are they available prior to lexicalization, as aspects of a first nature that humans may share with other animals? Or is lexicalizing available concepts a process of introducing distinctive concepts that can be fetched and combined via linguistic expressions? Or do we need another option?

In addressing these questions, I want to allow for concepts that are not as combinable as expressions that HFL can generate; cp. Spelke, 2002; Carruthers, 2002. For in acquiring words, we may use some concepts to make others. To foreshadow: suppose that acquiring 'kick' is a process in which a dyadic concept like $\operatorname{KICK}(\mathrm{X}, \mathrm{Y})$ is paired with a sound type, assigned an address in memory, and used to introduce a concept of events, $\operatorname{KICK}(\mathrm{E})$, that can later be fetched via the memory address and conjoined with other concepts. Then 'swift kick' and 'kick a brown cow' can be analyzed as instructions to build concepts like $\bullet[\operatorname{SWIFT}(\mathrm{E}), \operatorname{KICK}(\mathrm{E})]$ and $\bullet[\operatorname{kick}(\mathrm{E}), \exists \bullet[\operatorname{patient}(\mathrm{E}, \mathrm{x}), \bullet[\operatorname{Brown}(\mathrm{x}), \operatorname{COw}(\mathrm{x})]]$; where ‘ $\bullet$ indicates a

2 Prototypes and images, for example, may not; see Fodor and Lepore, 2002. And sets of possible worlds can be unstructured contents in Stalnaker's (1984) sense. 
conjunction operator that may be restricted to concepts of low adicity-while ' $\&$ ' can connect open sentences with any number of variables-PATIENT(E, $\mathrm{x}$ ) is a concept of a thematic relation exhibited by certain events and participants affected in those events, and ' $\exists$ ' existentially closes the participant variable (' $x$ '). Similarly, 'kick a carrot to a cow' can be an instruction to build a monadic concept like $\bullet[\bullet[\operatorname{Kick}(\mathrm{E}), \exists \bullet[\operatorname{patient}(\mathrm{e}, \mathrm{x}), \operatorname{CARrot}(\mathrm{x})]], \exists \bullet[\operatorname{Recipient}(\mathrm{E}, \mathrm{x}), \operatorname{Cow}(\mathrm{x})]]$, which applies to kicks that have carrots as patients and cows as recipients; cp. Parsons, 1990; Schein, 1993, 2002. ${ }^{3}$

On the view urged here, the concept initially lexicalized with (the sound of) 'kick' can differ formally from the concept subsequently fetched via this lexical item. In section two, I argue that lexicalized concepts differ, perhaps along several dimensions, from the concepts fetched. In section three, I argue that this formally creative aspect of lexicalization promotes cognitive integration, by giving us new concepts that fit together in recursively productive ways, at the cost of giving us concepts that fit the world less well than the concepts initially lexicalized. But let me be explicit about the operative conception of language, since some readers may find it odd to speak of linguistic expressions as instructions to fetch and combine concepts of any kind.

\subsection{Human I-Languages}

Humans are born with a capacity to acquire languages that are constrained, in various ways, yet still boundless in the sense that each such language has endlessly many expressions. So I assume that children acquire and somehow implement procedures that can generate endlessly many phrases, given finitely many lexical items that are somehow recursively combinable.

We can idealize, and say that these biologically implemented procedures (or algorithms) determine sets of expressions. But distinct algorithms can specify the same set. Letting ' $x$ ' and ' $y$ ' range over natural numbers, $\{<x, y>: y=|(x-1)|\}$ $=\left\{<x, y>: y=+\sqrt{ }\left(x^{2}-2 x+1\right)\right\}$. The procedures specified with ' $|(x-1)|$ ' and

3 I assume that thematic concepts like RECIPIENT(E, $\mathrm{x}$ ) - or perhaps GOAL(E, $\mathrm{x}$ ) - are available to lexicalizers. The complex concepts can be represented with more familiar notation: KICK(E) \& $\exists x[\operatorname{recipient}(\mathrm{E}, \mathrm{x}) \& \operatorname{Cow}(\mathrm{x})] \& \exists x[\operatorname{patient}(\mathrm{E}, \mathrm{x}) \& \operatorname{carrot}(\mathrm{x})]$. But this suggests that dyadic concepts like $\exists \mathrm{x} \exists \mathrm{y}[\operatorname{House}(\mathrm{z}) \& \operatorname{SAw}(\mathrm{x}, \mathrm{y}) \& \operatorname{Red}(\mathrm{y}) \& \operatorname{BETweEn}(\mathrm{w}, \mathrm{y}, \mathrm{z})]$ are also available. By contrast, ' $\bullet$ ' stands for a concept that can combine with two monadic concepts to yield a third, and ' $\exists$ ' stands for a concept that combines with a concept of the form $\bullet[\Theta(E, x)$, $\Phi(\mathrm{x})]$ to yield a monadic concept in which the variable of the constituent monadic concept is closed. Converting $\bullet[\mathrm{KILL}(\mathrm{E}), \exists \bullet[\operatorname{PATIENT}(\mathrm{E}, \mathrm{X}), \operatorname{COW}(\mathrm{x})]]$ into a sentential concept also requires variable closure, but not concepts of truth values. Imagine operators, $\Uparrow$ and $\Downarrow$, such that for any concept $\mathrm{C}(\mathrm{x}): \Uparrow \mathrm{C}(\mathrm{x})$ is a monadic concept that applies to everything if $\mathrm{C}(\mathrm{x})$ applies to something, and otherwise applies to nothing (cp. Tarski, 1933); $\Downarrow \mathrm{C}(\mathrm{x})$ applies to nothing if $\mathrm{C}(\mathrm{x})$ applies to something, and otherwise applies to everything. Then for each entity, $\Uparrow \mathrm{C}(\mathrm{x})$ applies to it iff $\exists x[C(x)]$, and $\bullet[\Uparrow C(x), \Downarrow D(x)]$ applies to it iff $\exists x[C(x)] \& \sim \exists x[D(x)]$; see Pietroski, forthcoming $a$. 
' $\sqrt{ }\left(x^{2}-2 x+1\right)$ ' are extensionally equivalent but intensionally distinct: the first calls for subtracting one from the input, and computing the absolute value of the result; the second calls for squaring the input, subtracting its double, adding one, and computing the result's positive square root. A mind might be able to implement the first algorithm but not the second; cp. Church, 1941; Marr, 1982. Chomsky (1986) thus urged us to focus on 'I-languages' - generative procedures, individuated intensionally — as opposed to any corresponding sets of expressions or 'E-languages.' This leaves room for the idea that children implement distinct but extensionally equivalent I-languages, and that the relevant procedures are individuated externalistically, allowing for duplicates who implement distinct procedures by virtue of inhabiting distinct environments. Like Chomsky, I suspect that such claims are false (see Pietroski, 2008) but use 'I-language' as a technical term that is neutral in these respects.

If expressions of a natural human language are generable by certain procedures, implemented by human biology, this constrains what the expressions can be. Moreover, comprehension and speech may be staged processes of using I-languages in tandem with other cognitive/motor systems that interact with generable 'I-expressions'. Using Chomsky's (1995) terminology, we can say that each I-expression pairs an instruction to 'articulatory-perceptual systems' with an instruction to 'conceptual-intentional systems'. This suggests an explanatory division beyond the usual force/content distinction (cp. Dummett, 1975): theories of I-languages are theories of the generative procedures that pair phonological instructions (PFs, PHONs) with semantic instructions (LFs, SEMs); other systems execute these instructions, thereby generating representations that figure in subsequent cognitive processes (see Figure 1).

We can think of an I-language as an algorithm that generates expressions via some combinatorics from a lexicon of atomic elements, each of which pairs one

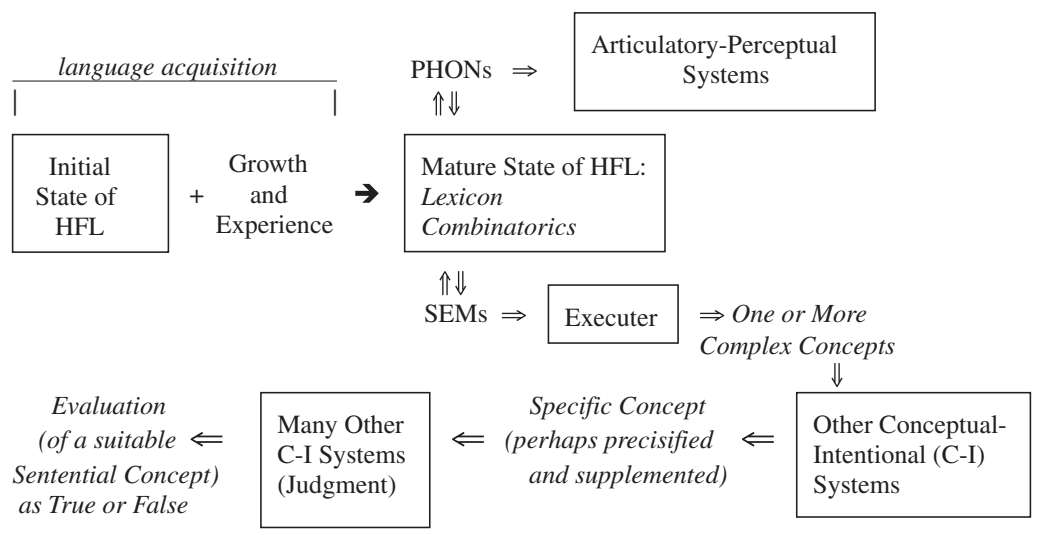

Figure 1 A possible etiology of judgment, with a significant role for HFL 
PHON with one SEM. If the meaning of an I-expression is its SEM, then each expression has exactly one meaning. But a single PHON may be paired (lexically or generatively) with more than one SEM, yielding homophony. And a single SEM can be polysemously linked to more than one concept.

For example, even if 'book a trip' and 'buy a book' illustrate the homophony of 'book', the latter meaning/SEM may be linked to both a concept we use to think about spatially located books and a formally distinct concept we use to think about abstract book contents. Perhaps one of these concepts is somehow dependent on the other; or perhaps both are dependent on some concept initially lexicalized with 'book'. But if two or more fetchable concepts share an address, then an instruction to fetch a concept from that address will be executable in more than one way, like an instruction to fetch a rabbit from a room with rabbits. So evaluating SEMs as if they were concepts may be a category mistake, like evaluating an instruction to fetch a rabbit as male or female; cp. Strawson, 1950. Moreover, even with polysemy resolved, concepts constructed via SEMs may require precisification and supplementation if the thinker is to form a sentential concept that can be evaluated for truth/falsity. As discussed in section three, concepts constructed via SEMs may be inputs to further processing that yields thoughts with constituents that better reflect the environment and less directly reflect HFL.

One can stipulate that SEMs are too mind-dependent, or too environmentindependent, to be meanings. ${ }^{4}$ But then I-expressions may not have meanings. If the facts explained by semantic theories for I-languages are best explained in terms of SEMs, then I would say that meanings are SEMs - compare the discovery that water is $\mathrm{H}_{2} \mathrm{O}$, modulo impurities - even if SEMs do not determine truth conditions, given values for their variables; cp. Putnam, 1975; Stanley, 2000. But however 'meaning' is defined, the issues concern the natural phenomenon of understanding and how I-languages are related to concepts.

\subsection{Combination Operations and Concept Creation}

One can view the grammatical combination of two lexical items as an instruction to fetch a concept via each lexical address and then apply a certain operation to the pair of concepts fetched. For example, (the SEM of) 'brown cow' might be an instruction to fetch a concept from each lexical address and conjoin them. And perhaps 'Bessie is a cow' is, modulo tense, an instruction to fetch a concept from each lexical address and saturate one with the other. An 'instructionist' conception of I-language semantics allows for views according to which different modes of grammatical combination call for different operations of conceptual combination. But it also allows for more constrained views.

\footnotetext{
4 Cp. Lewis' (1972) response to Katz and Fodor's (1963) proposal that a semantic theory associate expressions of the object language with expressions of 'Markerese'.
} 
One can hypothesize that all cases of combining expressions are instructions to saturate one concept with another. For even if the only concepts fetchable with 'brown' and 'cow' are Brown(x) and $\operatorname{cow}(\mathrm{x})$, one can say that in the noun phrase 'brown cow', the modifier 'brown' is an instruction to fetch BROWN(x) and use it to make a concept like $\bullet[\operatorname{BrOWN}(\mathrm{x}), \mathrm{X}(\mathrm{x})]$; where this higher-order concept can be saturated with $\operatorname{cow}(\mathrm{x})$ to form $\bullet[\operatorname{BrOwN}(\mathrm{x}), \operatorname{cow}(\mathrm{x})]$. On this view, some cases of combination call for fetching two concepts, performing a type-shift operation on one, and saturating the result with the other fetched concept; cp. Parsons, 1970; Kamp, 1975. Alternatively, one can say that all cases of combining expressions are instructions to conjoin a pair of concepts. For even if 'kick' calls for a concept of events, and 'cow' calls for a concept of individuals, one can say that the verb phrase 'kick a cow' is an instruction to make a concept like $\exists \bullet[\operatorname{PATIENT}(\mathrm{E}, \mathrm{x}), \operatorname{COw}(\mathrm{x})]$ and conjoin it with a concept fetched via the verb. On this view, some cases of combination call for fetching two concepts, performing a theta-shift operation on one, and conjoining the result with the other; cp. Carlson, 1984; Higginbotham, 1985.

Elsewhere, I have argued that a 'Conjunctivist' account of semantic composition is better than accounts that assume a basic operation of saturation; see Pietroski, 2005a, 2006a, 2008; Hornstein and Pietroski, 2009. And one can hypothesize that $\operatorname{KІСK}(\mathrm{E})$ is introduced, in terms of antecedently available concepts, roughly as follows (cp. Davidson, 1967a; Castañeda, 1967): $\operatorname{\kappa Іск}(\alpha, \beta) \equiv \exists \mathrm{E}[\operatorname{\kappa ick}(\mathrm{E}, \alpha, \beta)]$; $\operatorname{KICK}(\mathrm{E}, \alpha, \beta) \equiv \bullet[\operatorname{AGENT}(\mathrm{E}, \alpha), \bullet[\operatorname{KICK}(\mathrm{E}), \operatorname{PATIENT}(\mathrm{E}, \beta)]]$. I return to some details. For now, just let me stress that Conjunctivists are hardly alone in appealing to processes that use available concepts to create new ones, given constraints imposed by composition operations. Saturationists can - instead of positing a type-shift from $\operatorname{BROWN}(\mathrm{x})$ to $\bullet[\operatorname{BrOWN}(\mathrm{x}), \mathrm{X}(\mathrm{x})]$ for each case of combining 'brown' with a noun like 'cow' - say that in lexicalization, 'brown' is first linked to Brown(x), which is used to build $\bullet[\operatorname{BrOWN}(\mathrm{x}), \mathrm{X}(\mathrm{x})]$, which is then stored along with $\operatorname{BROWN}(\mathrm{x})$ as a concept that can be fetched via 'brown'.

One can eschew this appeal to creative lexicalization by positing a conjunctive composition operation: given lexical items that fetch monadic concepts like $\operatorname{BROWN}(\mathrm{x})$ and $\operatorname{COw}(\mathrm{x})$, form $\bullet[\operatorname{BrOwN}(\mathrm{x}), \operatorname{cow}(\mathrm{x})]$ directly, without forming - $[\operatorname{BrOWN}(\mathrm{x}), \mathrm{X}(\mathrm{x})]$. But then one has to ask if appeal to saturation is still required, as a composition operation, especially if there is evidence that lexicalization regularly creates monadic concepts. If 'kick a cow' is plausibly an instruction to build a concept like $\bullet[\operatorname{KICK}(\mathrm{E}), \exists \bullet[\operatorname{PATIENT}(\mathrm{E}, \mathrm{x}), \operatorname{COw}(\mathrm{x})]]$, and similarly for other cases of verbs combining with grammatical arguments, appeals to theta-shifting can be motivated as part of a larger theory according to which such shifts are invoked because phrases are uniformly instructions to conjoin concepts. This predicts that even proper nouns, like 'Brutus' and 'Caesar', call for monadic concepts. But as we'll see, this prediction seems to be correct, making it more plausible that phrases 'Brutus 
kick Caesar' are instructions to build concepts like $\bullet[\exists \bullet[\operatorname{AGENT}(\mathrm{E}, \mathrm{x}), \operatorname{BRUTUS}(\mathrm{x})]$,

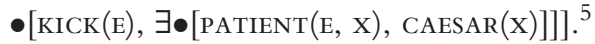

If combining expressions is never an instruction to saturate a concept, one might suggest that lexicalization creates concepts from representations that have no adicities. This radical proposal is compatible with my main claims. But I suspect that concepts, with diverse adicities, somehow emerged from primordial cognition long ago; my hypothesis is not that HFL is responsible for this mystery. A different worry is that my conception of HFL requires too much innovation for one species, even if other conceptions require more. Perhaps human children come equipped with lexicalizable monadic concepts like KICK(E), and some of our nonhuman ancestors used polyadic concepts to introduce conjoinable monadic analogs, though without the added trick of pronouncing generable SEMs; cp. Hurford, 2007. One can speculate that HFL, in its current form, is the result of adding a capacity for speech (or sign) to a faculty that was used intrapersonally. But since lexicalization now pairs concepts with PHONs, I speak of creative lexicalization as a process that occurs in infant human heads, if only for simplicity.

\section{Evidence of Reformatting}

In this section, I review some facts that suggest a striking constraint: when nonmonadic concepts are lexicalized with open-class vocabulary-nouns, verbs, and adjectives/adverbs - the resulting words fetch monadic concepts, as if semantic composition requires such concepts as inputs. ${ }^{6}$

5 If 'Antony saw Brutus hit Caesar' directs construction of $\bullet[\exists \bullet[\operatorname{EXPERIENCER}(\mathrm{E}, \mathrm{x})$, ANTONY(x)], $\bullet[\bullet[\operatorname{see}(\mathrm{E}), \operatorname{past}(\mathrm{E})], \exists \bullet[\operatorname{theme}(\mathrm{E}, \mathrm{x})$, Brutus-Hit-Caesar(x)]]]—cp. 'Antony saw a tree'-this handles the ambiguity of 'saw Brutus hit Caesar with a telescope'. The prepositional phrase can modify either verb; see Higginbotham, 1983. And this coheres with examples (see Taylor, 1985, crediting Gareth Evans) that bolster Davidson's (1967b) arguments for diagnosing such phrases as conjuncts of event predicates. Suppose Brutus poked Caesar softly with a red stick, and simultaneously poked him sharply with a blue stick. In addition to the Davidsonian predictions concerning implication, there are correctly predicted nonimplications: it doesn't follow that Brutus poked Caesar softly with a blue stick, or sharply with a red stick; what follows is that there was $a$ soft poke with a red stick, and $a$ sharp poke with a blue stick.

Perhaps other constructions motivate appeal to saturation as an additional operation; see, e.g., note 6. But Conjunctivists eschew this kind of 'compositional freedom,' describing HFL's creativity differently. And thematic contrasts like agent/experiencer can be described in terms of formal relations like EXTERNAL $(\mathrm{E}, \mathrm{X})$, with concepts like KICK $/ \operatorname{SEE}(\mathrm{E})$ introduced as follows (cp. Baker, 1997): Kick/SeE(E, $\alpha, \beta) \equiv \bullet[\operatorname{eXternal}(\mathrm{E}, \alpha), \bullet[\operatorname{KicK} / \operatorname{SeE}(\mathrm{E})$, internal(E, $\beta)]] ; \forall \mathrm{E}: \mathrm{KICK} / \mathrm{SEE}(\mathrm{E})[\operatorname{ACTION} / \operatorname{PERCEPTION}(\mathrm{E})] ; \forall \mathrm{E}: \operatorname{ACTION} / \operatorname{PERCEPTION}(\mathrm{E})[\bullet\{\forall \mathrm{x}[\operatorname{EXTERNAL}(\mathrm{E}, \mathrm{x})$ $\equiv$ agent/experiencer(E, $\mathrm{x})], \forall \mathrm{x}[\operatorname{InTERnAl}(\mathrm{E}, \mathrm{x}) \equiv \operatorname{Patient} / \mathrm{Theme}(\mathrm{E}, \mathrm{x})]\}]$.

${ }^{6}$ For any particular word, one can argue that the concept lexicalized was already monadic. And my view is not that we can just intuit the adicities of our concepts. On the contrary, I think many alleged paradigms of monadicity (like 'mortal') lexicalize relational concepts. If the concepts we lexicalize are massively monadic, it becomes hard to explain the relational 


\subsection{Singular Concepts}

Sentences like (1-4) suggest that the lexical item 'Caesar' can be used to fetch a monadic concept, and that in this respect, a lexical proper noun (LPN) is like the common noun 'tyrant'.

(1) Every Caesar I saw was a tyrant

(2) Every tyrant I saw was a Caesar

(3) There were three Caesars at the party

(4) That Caesar stayed late, as did this one, but the other Caesar left early

Of course, (5) is not a sentence of English. But the subject of (6) need not be a mere LPN.

(5) *Tyrant arrived

(6) Caesar arrived

In English, a name may be a complex expression consisting of an LPN and a covert determiner that combines with LPNs but not common nouns. On this view, the sound of 'Caesar' can be the sound of a bare LPN or a phrase whose head is silent; see Burge, 1973. But many languages have overt analogs of this distinction. For example, in Spanish, 'El Juan' can be used to refer to a certain Juan. And even English allows 'our John' ('my John', etc.) as a way of referring to a John who is suitably related to the speaker. 7

In examples like (7), 'Tyler' is readily heard as a surname.

(7) The Tylers are coming to dinner

But as surnames remind us, LPNs can be combined with honorifics or other LPNs, as in (8).

(8) Professor Plum talked about a proposal due to Tyler Burge

aspects of thought; though of course, some concepts may be acquirable only given significant language acquisition.

Quantification is complicated on any view. If 'kick' fetches $\operatorname{KICK}(\mathrm{x}, \mathrm{y})$ and 'every cow' directs construction of $\forall \mathrm{x}: \operatorname{COW}(\mathrm{x})$, 'kicked every cow' calls for type-shifting on a Saturationist account, even if raising (May, 1985) yields expressions like [[every cow $]_{1}$ [Brutus kicked $\left.\left.\mathrm{t}_{1}\right]\right]$. Since $\forall \mathrm{x}: \operatorname{COW}(\mathrm{x})$ can only be saturated by a monadic concept like KICK(BRUtus, $\mathrm{x}$ ), the index must conspire with [Brutus kicked $t_{1}$ ] to create an instruction to build such a concept, as opposed to a sentential concept of truth/falsity. (By contrast, a relative clause like 'who Brutus kicked' cannot saturate 'every cow'.) But given the requisite composition/abstraction principle, which quantifies over assignments of values to variables (as in Tarski, 1933), Conjunctivists can also accommodate raised quantifier constructions. See Pietroski, 2005a for comparison with Heim and Kratzer, 1998; cp. Jacobson, 1999.

7 Similar remarks apply to Basque, German, Scandinavian languages, many dialects of Italian, and Greek (mentioned below). I remain neutral about whether the relevant determiner is more like overt 'that', as in (4), or 'the'. For discussion of various syntactic/semantic details, see Longobardi, 1994; Elbourne, 2005; Matushansky, 2006; but cp. Segal, 2001. 
This leaves room for many proposals about the meanings of LPNs. Perhaps a singular concept like TYLER is used to build a concept like $=(\mathrm{x}$, TYLER $)$; cp. Quine, 1963. But if a singular concept $\mathbf{C}$ is associated with a phonological form $\boldsymbol{\pi}$, a mind that has the relational concept $\operatorname{CALLS}(\mathrm{X}, \mathrm{Y})$ could form the thought $\operatorname{CALLS}(\boldsymbol{\pi}, \mathbf{C})$. If such a mind had to use $\mathbf{C}$ to create a fetchable monadic concept, it might try $\operatorname{CALLS}(\boldsymbol{\pi}, \mathrm{x})$ - abbreviatable as $\boldsymbol{\Pi}(\mathrm{x})$ - especially if another singular concept $\mathbf{C}^{\boldsymbol{\prime}}$ is associated with $\pi$; cp. Katz, 1994. And $\Pi(x)$ can be conjoined with a contextsensitive concept that applies to the first thing demonstrated, or otherwise indexed in a situation, to form a concept like $\bullet[\operatorname{Indexes}(1, \mathrm{x}), \Pi(\mathrm{x})]$. On any such view, 'Tyler Burge' is semantically related to 'Tyler' and 'Burge', roughly as 'red ball' is to 'red' and 'ball': a Tyler Burge is both a Tyler and a Burge-i.e. someone called 'Tyler' and called 'Burge' - and likewise for a Professor Plum.

Monadic uses tell against treating LPNs as mere labels for singular concepts. But perhaps a speaker who uses 'Caesar' to talk about two people-Julius and Romero-uses three homophonous LPNs to fetch the concepts Julius, Romero, and CALlS(PHON: 'CAESAR', X). I cannot prove that this ambiguity hypothesis, positing 'singular-LPNs' and 'monadic-LPNs,' is false. But such hypotheses are generally unattractive; cp. Kripke, 1979. And if LPNs can fetch monadic concepts, we face puzzles if such nouns can fetch singular concepts.

If children could simply label singular concepts with certain nouns, and thereby acquire words that combine with verbs to form audible correlates of concepts like POKED(CAESAR), one would expect children to do just this. Such lexicalizers would become adults for whom examples like $(1-4)$ and $(7-8)$ would be defective: 'Every Caesar' would be like the nonsensical ' $\forall \mathrm{x}: c$ ', where ' $c$ ' is a logical constant. But instead, humans acquire LPNs that can be phrasal constituents, antecedents for the pro-form 'one', and pluralized. One can speculate that children accommodate $(1-4)$ by adding monadic-LPNs to their lexicons. But if lexicalizers can and do acquire monadic-LPNs, and examples like (6) can be handled without supposing that lexicalizers also acquire singular-LPNs, then theorists owe reasons for adopting an ambiguity hypothesis.

Given singular-LPNs, nouns would form a disjunctive grammatical class, and not just because of the two semantic types: singular-LPNs would not head recursively extendable phrases that also indicate singular concepts. Appeal to such nouns also raises questions about acquisition. For if any acquirable I-language has singularLPNs, then Universal Grammar does not preclude such nouns. Yet children acquire I-languages in which complex names, with monadic-LPNs as constituents, are the norm. For example, in Greek, LPNs are regularly accompanied by an overt determiner in argument positions; see e.g. Giannakidou and Stavrou, 1999. So if Greek children could but don't acquire singular-LPNs, contingent experience has to explain why they don't. Greek input must lead each normal child to a lexicon without too many LPNs, despite the possibility of singular-LPN analyses that would lengthen the lexicon. By contrast, English input must lead to a lexicon with enough LPNs, despite homophony and the possibility of monadic-LPN analyses that would 
shorten the lexicon. Perhaps this is so. But we should remember that ambiguity hypotheses have implications for acquisition.

Moreover, children treat phonological forms as homophonous only given reason to do so. So one might expect children to treat LPNs as monadic, in accord with common nouns like 'cow', absent evidence of homophony. One can conjecture that not hearing a determiner, in examples like (6), lets children know that English has singular-LPNs. But appeals to negative evidence in acquisition remains controversial, for good reason; see Crain and Pietroski, 2001. And here, the claim would be that children use negative evidence to acquire an I-language that exhibits theoretically superfluous ambiguities and an oddly disjunctive grammatical category.

At a minimum, actual use and acquisition of LPNs is strikingly compatible with the proposed generalization: when nonmonadic concepts are lexicalized with openclass vocabulary, the resulting words are used to fetch monadic concepts. With this in mind, let's consider cases in which the lexicalized concepts are plausibly 'supradyadic'. For such concepts seem to be lexicalized with I-expressions that fetch concepts of a lower adicity.

\subsection{Supradyadic Adicities}

If there are no 17-place concepts, the absence of verbs that take 17 arguments tells us little. But animal navigation seems to require polyadic representations; see Gallistel, 1990. And humans surely have concepts that are at least tetradic-e.g. $\operatorname{SELL}(\mathrm{X}, \mathrm{Y}, \mathrm{Z}, \mathrm{W})$ as opposed to $\operatorname{GIVE}(\mathrm{X}, \mathrm{Y}, \mathrm{Z})$, with ' $\mathrm{W}$ ' as a variable for what $\mathrm{z}$ transfers to $\mathrm{x}$ in exchange for $\mathrm{y}$, ignoring any event variable for simplicity. So why doesn't lexicalizing tetradic concepts yield words that fetch such concepts?

We could invent a language in which (9) is a sentence with the meaning of (10).

(9) ${ }^{\star}$ Mrs. White sold a knife Professor Plum ten dollars

(10) Mrs. White sold a knife to Professor Plum for ten dollars

But in English, (9) is anomolous, and 'sell' can combine with two arguments as in (11).

(11) Mrs. White sold a knife

The hypothesis that 'sold' fetches a tetradic concept, and that (11) has two covert arguments, is strained-especially as part of a proposal that eschews a covert constituent of names in English. And then what is wrong with (9)? Similar remarks apply to 'bought'. Though note that (12) is roughly synonymous with (13), using 'for' to signify a beneficiary; cp. (14).

(12) Professor Plum bought Miss Scarlet a knife

(13) Plum bought a knife for Scarlet

(14) Plum bought a knife for ten dollars 
Moreover, while (15) is acceptable, it is roughly synonymous with (16),

(15) Mrs. White sold Professor Plum a knife

(16) Mrs. White sold a knife to Professor Plum

suggesting a shared logical form in which 'Professor Plum' corresponds to a conjunct of the form $\exists \bullet[\operatorname{RECIPIENT}(\mathrm{E}, \mathrm{x}), \Pi(\mathrm{x})]$; where $\Pi(\mathrm{x})$ applies to the relevant professor called 'Plum'. In which case, 'sell' is not an instruction to fetch a triadic concept with a variable for recipients. One can say that 'sell' is an instruction to fetch a nonmonadic concept like $\operatorname{seLL}(\mathrm{E}, \mathrm{X}, \mathrm{Y})$ - as opposed to a monadic concept like $\operatorname{SELL}(\mathrm{E})$. But if the concept lexicalized has variables for the recipient and/or the payment, one wants to know why the concept fetched differs in this respect.

Such considerations bear on examples like (17) and (18).

(17) Scarlet gave Plum some money

(18) Scarlet gave some money to Plum

While (17) may initially support the idea that 'give' fetches a triadic concept, modulo any event variable, the prepositional phrase in (18) is - like its counterpart in (16) - plausibly analyzed as an instruction to build an eventish concept of the form $\exists \bullet[\operatorname{Recipient}(\mathrm{E}, \mathrm{x}), \Pi(\mathrm{x})]$. And the idea that 'give' fetches $\operatorname{Give}(\mathrm{x}, \mathrm{y}, \mathrm{z})$ or $\operatorname{GIVE}(\mathrm{E}, \mathrm{X}, \mathrm{Y}, \mathrm{Z})$ is unattractive in many respects. Famously, (19) contrasts with (20), suggesting that 'donate' does not fetch a concept that gets saturated by correlates of three grammatical arguments - or that such differences in acceptability need not reflect differing adicities of the concepts fetched; see Schein, 1993; Larson, 1988, forthcoming).

(19) Scarlet gave Oxfam some money

(20) * Scarlet donated Oxfam some money

In any case, 'donate' is plausibly a restricted form of 'give', requiring that the recipient be a charitable institution. And the acceptability of (21) is puzzling if 'give' fetches a triadic concept.

(21) Scarlet gave the money away

I return to examples like (22) and (23), which suggest that 'give' simply fetches GIVE(E).

(22) Some money was given away

(23) Plum gave at the office

More generally, ditransitive constructions like (17) can be analyzed in terms of a verb whose 'indirect object' is understood as part of a modifying phrase, as opposed to a grammatical reflection of a recipient variable in the concept fetched. The mere existence of such constructions cannot show that the verbs in such constructions 
fetch supradyadic concepts, else (24) would show the same about 'kick', making a puzzle of the synonymous (25), which implies (26). ${ }^{8}$

(24) Plum kicked Scarlet a knife

(25) Plum kicked a knife to Scarlet

(26) Plum kicked a knife

Likewise, we don't usually think of 'cooked' or 'sang' as fetching concepts with variables for recipients/beneficiaries. But consider (27).

(27) The cook cooked the colonel an egg, while he sang her a song

Moreover, verbs are not the only devices for indicating supradyadic relations. We understand (28), and presumably have a triadic concept BETWEEN(x, Y, z).

(28) Plum was between Scarlet and White

But evidently, this concept cannot be lexicalized with a verb 'bewtixt' as in (29),

(29) ^Plum betwixted Scarlet White

which sounds like a report of something Plum did to a certain Scarlet White. This is puzzling if, but only if, I-languages allow for predicates that fetch supradyadic concepts. One can speculate that such predicates are disallowed for reasons stemming from syntax of I-languages. But this fits ill with the idea that combining expressions often signifies saturation. If a mode of composition can be employed twice per clause, why not thrice or more? And if saturation is not available as a recursive mode of composition in clauses, why appeal to it, given an alternative? By contrast, if the recursive semantics is Conjunctivist, the absence of predicates that fetch supradyadic predicates is unsurprising - as is the presence of LPNs that fetch monadic concepts.

\subsection{Restricted Dyadicity}

If all open-class vocabulary items are used to fetch monadic concepts, then the verbs in transitive constructions like (30) do not fetch concepts with variables for the agent or patient.

(30) Plum kicked a knife

But let's go one step at a time.

Even if one assumes that 'kick' fetches a concept with a variable for things kicked, the optionality of Agent-representations like 'by Plum' in passive constructions like (31),

8 If only for simplicity, I have assumed that I-expressions have lexical items as terminal nodes. But one might think of I-expressions as instructions to build concept frames (see Ramchand, 2008), saying that a lexical item can be associated with several (hierarchically ordered) concept frames that apply to 'eventualities' of different sorts; cp. Dowty, 1979, 1991. 
(31) A knife was kicked;

suggests that 'kick' fetches $\operatorname{KICK}(\mathrm{E}, \mathrm{Y})$ as opposed to $\operatorname{KICK}(\mathrm{E}, \mathrm{X}, \mathrm{Y})$; where the former concept can be a constituent of $\exists \bullet[\operatorname{KICK}(\mathrm{E}, \mathrm{Y}), \operatorname{KNIFE}(\mathrm{Y})] .{ }^{9}$ And familiar accounts of causative constructions show how agent variables might be introduced by a functional element akin to the preposition 'by'. On such accounts, the verb in (32) also appears in (33), as indicated in (34).

(32) A glass broke

(33) Plum broke a glass

(34) [Plum [[v broke $]$ [ - [a glass $]]]]$

In which case, the overt verb need not fetch a concept with a variable for agents of breakings. This variable can be introduced by a morpheme that is covert in English but overt in many languages. So if 'break' fetches a concept with a variable for the broken, the optionality of Agent-representations suggests that 'break' fetches $\operatorname{BREAK}(\mathrm{E}, \mathrm{Y})$, which can be a constituent of a more complex concept that applies to a causal process that ends with a glass breaking: $\bullet$ [TERMinATER $(\mathrm{C}, \mathrm{E}), \exists \bullet[\operatorname{BREAK}(\mathrm{E}$, $\mathrm{Y})$, GLASS(Y)]]; where this monadic concept can be conjoined with $\exists \bullet[\operatorname{AGENT}(\mathrm{C}, \mathrm{X})$, $\operatorname{PLUM}(\mathrm{x})$ ], ignoring complexity within names for simplicity. ${ }^{10}$

Of course, my suggestion is that 'break' and 'kick' fetch BREAK(E) and кICK(E), as suggested by the nominal uses illustrated in (35); cp. Parsons, 1990; Schein, 1993.

(35) There is a break in the window from when Mr. Green gave it a swift kick If these lexical items fetch concepts with variables for the kicked/broken, examples like (36),

(36) The hustler broke, sinking the eight ball, and the baby kicked

also call for special treatment. And many facts concerning plurality suggest that all variables for thematic participants are severed from concepts fetched via verbs; see

9 See Chomsky, 1995; Kratzer, 1996. One can posit a process of passivization that creates KICK(E, $\mathrm{Y})$ from $\operatorname{KICK}(\mathrm{E}, \mathrm{X}, \mathrm{Y})$, and a process of nominalization that creates $\mathrm{KICK}(\mathrm{E})$ to handle examples like (35) below. But this invokes two grammatical processes to do the work of independently motivated Conjunctivist lexicalization; see Borer, 2005 for related arguments.

10 Cp. Baker, 1988. But my proposal does not require that the verbs in causative constructions lexicalize monadic concepts from which the corresponding causal concepts are built; cp. Fodor and Lepore, 2002. A neo-Davidsonian mind might use BREAK(x, y) to introduce BREAK(E) - a concept of causal processes that have agents and patients - and a second monadic concept BREAK(F) such that $\exists \bullet[$ TERMinATER(E, F), BREAK(F)] $\equiv$ BREAK(E); cp. Levin and Rappaport, 1995. See Pietroski, 2005a for discussion of terminater(E, $\mathrm{x}$ ) and its relation to Patient(E, $\mathrm{x}$ ). 
Schein, 1993, 2002, forthcoming. ${ }^{11}$ But since I cannot defend this view in detail here, let me stress three points.

First, if the concept lexicalized with 'kick' has a variable for kickers, one wants to know why the verb fetches $\operatorname{KICK}(\mathrm{E}, \mathrm{Y})$ as opposed to $\operatorname{KICK}(\mathrm{E}, \mathrm{X}, \mathrm{Y})$ - and how this kind of creative lexicalization works without leading to a verb that fetches KICK(E). Second, if LPNs correspond to monadic concepts like PLUM(x), and the subject of (30) corresponds to a thematic conjunct in a concept of events, the remaining debate concerns whether (30) calls for construction and existential closure of a monadic concept like (35) or (36).

(35) $[\exists \bullet[\operatorname{AgENT}(\mathrm{E}, \mathrm{X}), \operatorname{PLUM}(\mathrm{X})], \bullet[\operatorname{KiCK}(\mathrm{E}, \mathrm{Y}), \operatorname{KNIFE}(\mathrm{Y})]]$

(36) $[\exists \bullet[\operatorname{agent}(\mathrm{E}, \mathrm{X}), \operatorname{PLum}(\mathrm{X})], \bullet[\operatorname{KiCK}(\mathrm{E}), \exists[\operatorname{PATIENT}(\mathrm{E}, \mathrm{Y}), \operatorname{KNIFe}(\mathrm{y})]]$

Either way, saturation plays very little role, raising the question of whether theorists should appeal to saturation as a recursive composition operation. Third, one can do without such appeal, even if one wants to preserve the idea that (30) calls for construction of (35). For in an important sense, $\operatorname{KICK}(\mathrm{E}, \mathrm{Y})$ is no more relational than PATIENT(E, Y).

Let me expand on this last point. On my view, complex SEMs are instructions to build monadic concepts. But my claim is not that the concepts built have only monadic constituents. On the contrary, thematic concepts like AGENT(E, x) play a crucial role. But while such concepts are formally dyadic, events are not independent of their participants: without Plum, there cannot be any event that has Plum as its agent. In this respect, thematic concepts are unlike prototypically relational concepts like LOVes $(\mathrm{X}, \mathrm{Y})$ or $\operatorname{TALleR}(\mathrm{X}, \mathrm{Y})$ or the concept $\operatorname{KICK}(\mathrm{X}, \mathrm{Y})$ that applies to kicker-kickee pairs. But KICK(E, Y) - or better, KICK-OF(E, Y) - is relevantly like PATIENT(E, Y); given an event-individual pair that satisfies the concept, the event is not independent of the individual. If verbs are limited to fetching concepts of such 'restricted relations,' one wants to know why, if combining verbs with arguments can signify saturation.

Prepositions can apparently fetch thematic concepts, as illustrated by (37),

(37) a stab of Plum with a knife

11 Kratzer (1996) argues - stressing subject/object asymmetries in passivization and idioms (see Marantz, 1984) - that while agent variables are 'severed' from the semantic contribution of verbs, this contribution remains polyadic: combination with a direct object indicates saturation of a variable, yielding a concept like KICK(E, CAESAR); see also Harley, 2006. But this still presupposes creative lexicalization, unless the hypothesis is that (i) concepts like $\operatorname{KICK}(\mathrm{E}, \mathrm{X})$ are available for labeling, and (ii) concepts of higher adicity are not. So absent independent arguments for (i), one might accept arguments for severing all participant variables from the contributions of verbs, and blame any asymmetries on cognitive factors independent of semantic composition, instead of positing distinct composition operations for subjects and objects. Williams $(2007,2009)$ defends such a diagnosis, arguing that Kratzer's claims to the contrary are unpersuasive for English and implausible when applied to good test cases in other languages. 
or concepts of more prototypical relations, as illustrated by (38).

(38) a book on a shelf in a library

(38а) •[воOK(x), $コ \bullet[\mathrm{ON}(\mathrm{x}, \mathrm{y}), \bullet[\operatorname{shelf}(\mathrm{y}), \exists \bullet[\operatorname{IN}(\mathrm{y}, \mathrm{z}), \operatorname{Library}(\mathrm{z})]]]]$

Prepositions are polysemous. But 'book on a shelf may direct construction of a concept of shelf-states whose subjects are books: $\bullet[\exists \bullet[\operatorname{SUBJECT}(\mathrm{s}, \mathrm{x}), \operatorname{BOOK}(\mathrm{x})], \bullet \exists[$ ON $(\mathrm{s}$, Y), Shelf(Y)]]; cp. Parsons, 1990; Svenonius, forthcoming. Like the stative predicate 'open', 'on a shelf' can combine with a tensed copula as in (39); cp. Baker, 2003.

(39) A book is/was on a shelf

But while we can imagine a corresponding tensed verb, (40) is defective.

(40) $\star$ A book ons/onned a shelf

The relational concept indicated with '(be) on' is not lexicalized with a verb that fetches this concept. Likewise, (41) is anomalous; circumlocution is required, as in (42).

(41) ^Plum froms Devon

(42) Plum hails from Devon

And we use (43), not (44), as if $\operatorname{FrOM}(\mathrm{X}, \mathrm{y})$ and TALLER(X, Y) cannot be fetched via verbs. $^{12}$

(43) Plum is taller than Green

(44) ^Plum talls Green

To be sure, strings like (45) and (46) are anomalous.

(45) $\star$ Scarlet sent

12 The concept lexicalized with 'jimmied' presumably has a variable for an implement. Yet any reference to an implement appears in a modifying adjunct, as in 'jimmied the lock with a knife'; $c$ *'jimmied the lock a knife'. (See Williams, 2007.) One might think that 'tall' fetches a concept of a relation exhibited by entities like Plum and abstracta like heights; cp. Kennedy, 1999. But circumlocution is still required: we say 'Plum is that tall', not 'Plum talls that'. Comparative adjectives do show that many cases of adjunction, like cases of combining with arguments, invoke more than mere conjunction of concepts. But a big ant is still an ant that meets another condition. And 'big' may combine with a covert anaphor, with 'big ant' as an instruction to form a monadic concept: $\exists \bullet[B I G-O N E(X, Y)$, THE-ANTS(Y)]; where BIG-ONE(X, Y) can be satisfied by a thing, $\mathrm{x}$, and some things, the $\mathrm{Ys}$, such that $\mathrm{x}$ is both a $\mathrm{Y}$ and a big one. See Higginbotham, 1985 on 'autonymous' theta-marking and Pietroski, 2006b for elaboration in a Conjunctivist account of plural and comparative constructions, drawing on Boolos, 1998. Other examples require other analyses. But if $\mathrm{x}$ is a fake diamond, there was a faking whose intentional content was (roughly) that $\mathrm{x}$ seem to be a diamond; see Pietroski, 2005a on events and contents. 
(46) $\star$ Plum put a book

But (47) and (48) still motivate the claim that 'send' and 'put' fetch SEND(E) and $\operatorname{PUT}(\mathrm{E})$.

(47) Scarlet sent for help

(48) A book stayed put

One can describe the unacceptability of (45) and (46) by adding-as a hypothesis about lexical knowledge - that 'sent' typically requires specification of a patient, and that 'put' requires specification of a location. But this is not to say that HFL precludes (45) or (46), much less that they are precluded by principles of semantic composition; cp. Borer, 2005. Since many verbs are flexible with regard to the number of nominal expressions they can/must combine with, it seems that any plausible view will distinguish the 'Semantic Composition Adicity Numbers' (SCANs) of lexical predicates - the adicities of concepts fetched - from the corresponding 'Lexicalized Adicity Numbers' (LANs). The latter may better reflect a given verb's Property of Smallest Sentential Entourage' (POSSE), corresponding to the number of arguments/adjuncts that must appear with the verb in a declarative sentence with active voice.

Given such a distinction, one can say that while SCANs are uniformly monadic, POSSEs vary in part because LANs vary; see Pietroski, forthcoming $b$. By itself, this leaves some generalizations uncaptured; see Hale and Keyser, 1993; Levin and Rappaport, 1995; Levin and Rappaport Hovay, 2005; Harley, 2006; Ramchand, 2008. But these generalizations may reflect aspects of the I-languages we actually use, not essential aspects the I-languages acquirable via HFL. So perhaps the generalizations should not be encoded in terms of a theory according to which I-language expressions can be instructions to fetch and saturate polyadic concepts. An otherwise attractive Conjunctivist conception of semantic composition can motivate alternative diagnoses of lexical flexibility.

\subsection{Reformatting Beyond Adicity}

I have focused on adicity as one dimension in which lexicalizable concepts can differ from their fetchable counterparts. But there are other such dimensions.

We can think about some cows as such, and think about them as many, or as constituting a herd. So we have plural concepts like $\operatorname{COws}(\underline{\mathrm{x}}), \operatorname{MANY}(\underline{\mathrm{x}})$, and CONSTITUTE-A-HERD $(\underline{\mathrm{x}})$; where underlining indicates a nonsingular variable. Such concepts exhibit an important distinction. Intuitively, some things are cows just in case each of them is a cow: $\forall \underline{x}\{\operatorname{Cows}(\underline{\mathrm{x}}) \equiv \forall \underline{\mathrm{x}} \underline{\mathrm{xx}}[\operatorname{COw}(\mathrm{x})]\}$; where ' $\underline{\mathrm{x}}$ ' can be glossed as ' $\mathrm{x}$ is one of the $\mathrm{xs}$ ' ${ }^{13}$ Correlatively, $\operatorname{COW}(\mathrm{x})$ is distributive: if two or

13 One can also gloss ' $\mathrm{xx}$ ' as ' $\mathrm{x}$ is an element of $\mathrm{x}$ '; cp. Quine, 1963; Link, 1983. But Boolos (1998) provides an alternative, allowing a plural variable to have many values relative to each 
more things satisfy this concept, each of them does. By contrast, no distributive concept $\Phi(\mathrm{x})$ is such that $\forall \underline{\mathrm{x}}\{\operatorname{MANY}(\underline{\mathrm{x}}) \equiv \forall \mathrm{x}: \underline{\mathrm{Xx}}[\Phi(\mathrm{x})]\}$. In this sense, MANY( $\underline{\mathrm{x}})$ is irreducibly plural. No one thing is many, not even a set with many elements. So prima facie, nothing is such that it satisfies MANY $(\underline{x})$ - even if $\operatorname{cows}(\underline{x})$ abbreviates $\forall \mathrm{x}: \mathrm{x} \in \mathrm{x}[\operatorname{COw}(\mathrm{x})]$ and is satisfied by each nonsingleton set of cows. But some cows can together satisfy MANY $(\underline{\mathrm{x}})$, even if no cow does. And on an understanding of 'constitute' that precludes self-constitution, no one thing constitutes a herd of cows, though some (elements of a set of) cows can.

Irreducibly plural concepts are not hard to find. But among our lexicalized concepts, they may be a minority. And our other lexicalized concepts may be nonplural. The concepts available for lexicalization may divide into distributive concepts like $\operatorname{COw}(\mathrm{x})$, which can be constituents of concepts like $\forall \mathrm{x}: \mathrm{xx}[\mathrm{COW}(\mathrm{x})]$, and irreducibly plural concepts like MANY(x). One can imagine lexicalizing a concept that is number neutral in the following sense: it can be satisfied distributively by each of one or more things and satisfied nondistributively by some entities no one of which satisfies the concept. But one can also-and more easily-imagine a mind limited to concepts like $\operatorname{COW}(\mathrm{x})$ and a few concepts like $\operatorname{MANY}(\underline{\mathrm{x}})$, which combine with others via the higher-order relational concept $\forall \mathrm{x}: \mathrm{xx}[\Phi(\mathrm{x})]$, yielding concepts like $\bullet[\operatorname{MANY}(\underline{\mathrm{x}}), \forall \mathrm{x}: \mathrm{xx}[\mathrm{COW}(\mathrm{x})]]$.

Perhaps human I-languages reflect such a mind, and 'cows' serves as an instruction to fetch the higher-order concept (via the plural morpheme) and saturate it with COw(x); see Link, 1983; Schwartzschild, 1996; Chierchia, 1998. But there is another option. Suppose that in lexicalization, $\operatorname{COW}(\mathrm{x})$ and $\operatorname{MANY}(\underline{\mathrm{x}})$ are used to introduce $\operatorname{COW}(\aleph)$ and $\operatorname{MANY}(\aleph)$, concepts with number-neutral variables that can have one-ormore values relative to each assignment of values to variables; see Boolos, 1998; Pietroski, 2005a, 2006a. This is compatible with lexical items imposing various restrictions on variables: one-or-more things are values of $\operatorname{cow}(\aleph)$ iff each is a value of $\operatorname{COW}(\mathrm{x})$; one-or-more things are values of MANY $(\aleph)$ iff they are many - and hence, more than one. Then 'cows' can be a simple instruction to fetch and conjoin the concepts $\operatorname{COW}(\aleph)$ and PLURAL( $($ ), with the latter fetched via the plural morpheme.

Variables in thematic concepts can also be characterized in number-neutral terms. We can say of some events and entities that the latter are the patients of the former, meaning roughly that each entity is the patient of an event, and each event has as an entity as its patient. Then 'kick cows' can direct construction of $\left.\bullet\left[\operatorname{Kick}(\aleph), \exists \bullet\left[\operatorname{PATIENT}(\aleph,)^{\star}\right), \bullet\left[\operatorname{COW}\left(\aleph^{\star}\right), \operatorname{PluRAL}\left(\aleph^{\star}\right)\right]\right]\right]$, which applies to oneor-more things (the $\aleph$ s) iff: each is a kick; and one-or-more things (the $\aleph^{\star}$ ) are such that they are the patients of the $\aleph$ s, each is a cow, and they are more than one. Similar remarks apply to 'branded fifty cows with twenty irons', which can combine with a singular or plural subject; and a subject like 'Five ranchers' can

assignment of values to variables. See Pietroski, 2006a for discussion of why this preserves the virtues, but not the vices, of appealing to lattice structures in a semantics for plural constructions. 
be understood distributively, implying that each rancher branded fifty cows, or collectively. The collective reading, which implies only fifty brandings, implies nothing about how the cows and irons were distributed across those who got the work done. And this neutrality is captured if each thematic role has its own conjunct, like $\exists[\operatorname{INSTRUMENT}(\aleph, \aleph \star), \bullet[\operatorname{IrON}(\aleph), \operatorname{TWENTY}(\aleph)]]$, in the constructed concept.

This point extends to examples like (49), which exhibits a 'semi-distributive' reading:

(49) Three trainers taught five dogs four tricks yesterday

three trainers together taught four tricks to each of five dogs, for a total of twenty processes of teaching a dog a trick - perhaps with more than one trainer involved in a given trick-teaching, but with no implication (or prohibition) of cooperation. And as Schein (1993, 2002, forthcoming) argues, such facts tell against analyses in terms of polyadic concepts like TEACH(E, $\underline{\mathrm{X}}, \underline{\mathrm{Y}}, \underline{\mathrm{z}})$ that are satisfied by $n$-tuples of collections of events/trainers/dogs/tricks. But even setting such examples aside, relative clauses like 'who branded fifty cows with twenty irons yesterday' apparently correspond to concepts that can be satisfied by one individual who did a lot of work, or by several individuals who together did the requisite branding (with or without cooperation).

If the composition operations invoked by human I-languages operate on concepts with number-neutral variables, but the concepts we lexicalize are not numberneutral, then lexicalization is a process in which concepts like $\operatorname{cow}(\mathrm{x})$ and $\operatorname{MANY}(\underline{\mathrm{x}})$ are used to create 'bleached' analogs like $\operatorname{COW}(\aleph)$ and $\operatorname{MANY}(\aleph)$; see Pietroski, 2005a, 2006a, forthcoming $a$ and $b$. Likewise, I claim, lexicalization bleaches adicity distinctions in order to employ operations that require monadic inputs. ${ }^{14} \mathrm{I}$ suspect there are still other respects in which lexicalization creates bleached concepts that can be combined via simple operations. But let me turn to some implications of the idea that monadicization is one aspect of such bleaching.

\section{Truth, Systematicity, and Fit}

Consider the following conjecture, which I have come to doubt: lexical expressions of a human I-language are true of various things, relative to assignments of values to

14 More speculatively, one might hope to accommodate mass nouns like 'water' and 'wood' in terms of a variable that is neutral as between one-or-more things or 'some stuff', with 'chop (some) wood' as an instruction to build $\bullet[\operatorname{CHOp}(\aleph), \exists \bullet[\operatorname{PATIENT}(\aleph, \aleph \star), \operatorname{woOD}(\aleph \star)]]$; where WOOD $(\aleph \star)$ applies, mass/count-neutrally, to (any sample of) wood. One could then distinguish $\operatorname{PIZZA}\left(\aleph^{\star}\right)$ from $\bullet\left[\operatorname{PIZZA}\left(\aleph^{\star}\right)\right.$, COUNTABLe $\left.\left(\aleph^{\star}\right)\right]$, or $\bullet\left[\operatorname{PiZZA}\left(\aleph^{\star}\right)\right.$, COUNTABLE-AS- $(\aleph \star$, PIZZA)], to distinguish 'ate some pizza' from 'ate a pizza'; cp. Gillon, 1987; Chierchia, 1998. 
any variables in such expressions; given these lexical satisfaction conditions, composition operations determine satisfaction conditions for complex expressions; and for each sentential expression, its satisfaction condition determines a truth condition.

So formulated, Truth Conditional Semantics sounds like a claim about E-languages; cp. Davidson, 1967b; and Montague, 1974; inspired by Tarski, 1933. But one can hypothesize that lexical I-expressions are instructions to fetch concepts that are true of certain entities, and that phrasal syntax directs construction of complex concepts whose satisfaction conditions are determined in accord with the relevant composition operations; cp. Larson and Segal, 1995. On this view, I-expressions do not have satisfaction conditions in the same way that concepts do: the semantic instruction issued by 'cow' is satisfied by fetching a concept that has a Tarskian satisfaction condition. And a polysemous expression like 'book', or 'satisfy', may not determine a Tarskian satisfaction condition. Still, one might say that each I-expression directs construction of a concept that has a compositionally determined satisfaction condition, with sentences as special cases that direct construction of truth-evaluable thoughts. But this assumes that the concepts fetched with I-expressions have the requisite satisfiers. ${ }^{15}$

\subsection{Locked Concepts and Integrated Concepts}

If our 'I-fetchable' concepts are systematically combinable because they were introduced to ensure such combinability, then these concepts lie at greater remove from the environment than the concepts we lexicalize (henceforth, L-concepts). Forming I-fetchable concepts, as opposed to L-concepts, requires an additional kind of abstraction that may be distorting. And if I-fetchable concepts must be monadic, with variables for eventish things (states, changes, processes, etc.), they may indeed fit the world less well than L-concepts; cp. Chomsky, 2000. I'll spend the rest of the paper saying why. But first, let me stress that if L-concepts are not systematically combinable-because they come from disparate languages of thought, as countenanced in section one-they may not fit each other in ways that support truth-evaluable judgments.

Suppose the unsaturated concepts $\mathrm{C}(\alpha, \beta)$ and $\mathrm{T}(1,2,3)$ cannot appear in concepts like $\exists \mathbf{v} \sim \exists \mathbf{v} \sim\left[\mathrm{C}\left(\mathbf{v}, \mathbf{v}^{\prime}\right) \& \mathrm{~T}\left(\mathbf{v}^{\prime}, \mathbf{v}^{\prime}, \mathbf{v}\right)\right]$. Then in my view, saying that $\mathrm{C}(\alpha, \beta)$ and $\mathrm{T}(1,2,3)$ are true of certain ordered pairs/triples overintellectualizes the concepts, or underintellectualizes truth. Setting aside abstracta that have truth conditions by stipulation, being true or false may well be a property exhibited only by structured representations of a special kind, or actions of using such representations to make judgments; cp. Frege, 1918; Fodor, 1975, 2003; Strawson, 1950. We can call these representations Thoughts (Gedanken). But then we cannot assume that forming a Thought is simply a matter of saturating the empty slots of an unsaturated

\footnotetext{
15 One might insist that even if I-fetchable concepts have no satisfiers, existential closures of such concepts can still be false; see note 3. But as we'll see, even this is not clear.
} 
L-concept. Forming judgments, as opposed to mere sentences of a mini-mentalese, may require systematically combinable concepts that exhibit genuine logical relations - so that the truth of any one potential judgment can be a consequence, in a logic the thinker accepts, of other potential judgments; cp. Evans' (1982) Generality Constraint on concepts. Though as Evans also discusses, mere systematicity is not enough for truth/falsity.

Given concepts that denote nothing-Vulcan, Phlogiston(x), etc. - it seems all too possible to have untrue thoughts that are too unhinged from reality to be false. But let's suppose, optimistically, that many of our L-concepts are 'locked onto' aspects of reality. Otherwise, it becomes even harder to explain how humans can have any concepts that figure in truth-evaluable judgments. We can be agnostic about the details. Perhaps such locking consists in (canonical uses of) the concepts carrying information, bearing certain causal relations to the environment, or having the right kind of natural history. ${ }^{16}$ But one can be optimistic without being credulous.

In particular, let's not ignore the fact that we use words in ways that are sensitive to many details of conversational situations. Like Chomsky (1977, 2000), I doubt that HFL generates expressions with enough variables to encode all the relevant kinds of context dependence; see Pietroski, 2005b. For example, the specific judgment expressed with (50):

(50) The sky is blue

can depend on many situational details, in apparently open-ended ways; cp. Travis, 1985, 1996. One can use (50) to talk about the 'local' sky. And even if one insists that 'rained' directs construction of a concept with a variable for a contextually determined place, it is hardly obvious that some constituent of (50) directs construction of a context-sensitive concept that applies to the sky in - skies of? bits of sky-stuff above? - a contextually determined place. Local standards also differ: blue for London may not count in Tucson. One can also use (50) to make a correct remark on a cloudy day, at night; etc. And pace Stanley (2000), I don't think the appeal of Truth Conditional Semantics motivates appeal to all the requisite indices in expressions generated by HFL. If meanings are instructions to build concepts, we can grant that I-expressions have some covert indices, but not enough to track all the ways in which truth can depend on context. ${ }^{17}$

16 Or perhaps many concepts are used in ways that make some uses explanatorily basic in that other uses depend on these (but not vice versa), and/or these uses track explanatorily important aspects of the environment; see Rey, 2009. I cannot discuss deflationary accounts of truth, or their relation to invented languages that allow for instances of 'True ('S') $\equiv \mathrm{S}$ '. But if I-expressions like 'Snow is white' are neither true nor false, the same is true for 'Snow is white is true if and only if snow is white'. And deflationary conceptions of meaning, as in Horwich, 1998, do not capture semantic constraints on I-expressions; see Pietroski, 2000.

17 And we cannot ignore the polysemy of words used to formulate hypotheses about which aspects of reality L-concepts are allegedly locked onto. If a lexical item $\lambda$ can be used to fetch 
Moreover, the meanings of indices are subject to constraints imposed by composition operations. If these operations are conjunctive, one might expect indices as in ' $\operatorname{him}_{1}$ ' to fetch context-sensitive concepts like $\operatorname{Indexes}(1, \mathrm{x})$ that can appear in complex concepts like $\bullet[\operatorname{KiCK}(\mathrm{E}), \exists \bullet[\operatorname{Patient}(\mathrm{E}, \mathrm{x}), \bullet[\operatorname{IndeXeS}(1, \mathrm{x}), \operatorname{MALE}(\mathrm{x})]]]$; cp. section 2.1 above. One can posit indices that fetch concepts of other types. But if our inquiry concerns I-languages, we have to ask if HFL really generates expressions with constituents that fetch such concepts. Since our task is not merely to associate I-expressions with abstracta that compose in some sense (see Szabó, 2000), we want more than mere specifications of functions as possible values for alleged indices; $\mathrm{cp}$. Pietroski et al., 2009. The facts illustrated in section 2 suggest constraints - if not Conjunctivist, then others - on the space of I-fetchable concepts. So the question is whether given these constraints, I-expressions have enough indices to track all the ways in which the truth of judgments can depend on context; cp. Bach, 1994; Carston, 2002; Recanati, 2004.

Eventually, we must also abandon the pretense that I-fetchable concepts have extensions. These concepts are typically vague, often in context-sensitive ways; see Fara, 2000. Indeed, the concepts we construct via HFL may be vague in multiple ways left unresolved by any indices in I-expressions. We can 'sharpen' concepts in contexts; see, e.g. Kamp, 1975. But prima facie, refinements follow construction of concepts formed by executing semantic instructions. And on the view urged here, vagueness is no threat to semantic composition. The phrase 'brown cow' can call for conjunction of concepts fetched via 'brown' and 'cow', even if these concepts lack 'boundaries' that determine extensions; see Sainsbury, 1996.

More generally, my claim is that phrases direct construction of concepts that exhibit only certain forms-• $[\Phi(\aleph), \Psi(\aleph)]$ or $\exists \bullet[\Phi(\aleph), \Theta(\aleph, \aleph \star)] —$ not that phrases are instructions to build concepts whose satisfiers meet certain conditions (e.g., being the brown cows). But one can posit a process that takes concepts like $\bullet[\operatorname{BrOWN}(\aleph)$, $\operatorname{COw}(\aleph)]$, along with representations of certain contextual information, and returns sharpened concepts like $\bullet[1(\operatorname{BROWN}(\aleph)), 2(\operatorname{COW}(\aleph))]$ that have extensions relative to assignments of suitable functions to the indices. Perhaps we can use I-concepts and other cognitive talents to create symbols of a mental language that allows for conjunctions of indexed correlates of I-concepts; where the indices, unavailable to HFL, track aspects of contexts that are relevant to the use of concepts in making truth evaluable judgments.

Still more generally, one might regard I-expressions as 'primal sketches' of judgments; cp. Marr, 1982. When presented with (the PHON of) such a sketch, making a judgment of truth or falsity may be a staged process in which a SEM is used to build a concept that is (not the concept judged with, but rather) used as input to further processing that results in a sentential concept used in judgment. As

any one of several concepts $(\mathrm{C} 1, \ldots \mathrm{Cn})$, there need not be any property or relation that $\lambda$ denotes. So we should be unimpressed by claims like the following: $\operatorname{BOOK}(\mathrm{x})$ is locked to the property of being a book; $\operatorname{GIVE}(\mathrm{x}, \mathrm{Y}, \mathrm{z})$ is locked to the relation of giving; etc. 
Stanley (2002) stresses, such processing must respect constraints; we do not modify the results of executing SEMs at whim. But I see no reason for thinking that all the constraints are enforced by HFL, and hence that HFL is sufficiently unconstrained to allow for indices that track all the ways in which truth can depend on context.

The issue is how to account for both (i) facts that suggest a constrained HFL, which generates SEMs whose execution yields 'I-concepts' of a restricted sort and (ii) facts that suggest constraints on processes that convert I-concepts into the judgments we evaluate for truth/falsity. I have stressed the former in part because I suspect we know even less about the latter. For theorists, the hard work may well lie with developing accounts of how I-concepts are used in the process of making judgments. But if so, we shouldn't try to provide algorithms that associate sentential I-expressions with compositionally determined truth conditions in one fell swoop. We should try to provide (a) theories of SEMs and how executing them can generate I-concepts that respect whatever constraints such concepts satisfy, and (b) theories of the processes that take I-concepts as inputs, along with representations of additional contextual factors, and yield (perhaps in a staged way) sentences of a human mentalese that can be endorsed or negated. Indeed, talk of sentences may already reflect interactions between HFL and judgment-making systems, as opposed to I-expressions of some special syntactic type.

Returning to a potentially deep problem for Truth Conditional Semantics, I see no reason for thinking that every relation tracked by an L-concept can be specified in terms of properties of events and a few thematic relations. One can say that a concept like $\operatorname{GIVE}(\mathrm{X}, \mathrm{Y}, \mathrm{z})$ is used to introduce a concept like GIVE(E) without saying that this mental process reflects an independent ontological order. The monadic concept can be introduced and used whether or not there are givings - in addition to givers, recipients, and things given — that satisfy concepts like $\bullet[\operatorname{GIVE}(\mathrm{E})$, $\bullet \exists[\operatorname{Theme}(\mathrm{E}, \mathrm{x}), \operatorname{BOne}(\mathrm{x})]]$. And even if there is a give, when one gives a dog a bone, is there also a give when one gives a friend a cold? Does a rope that has some give have something that satisfies a concept fetched via 'give'? One can say that I-languages let us construct concepts like $\bullet[\operatorname{GIVE}(\mathrm{E}), \bullet \exists[\operatorname{THEME}(\mathrm{E}, \mathrm{x}), \operatorname{COLD}(\mathrm{x})]]$, without assuming that some monadic concept GIVE(E) - introduced because semantic composition operations require such concepts as inputs - is satisfied by events that have colds as Themes; cp. Chomsky, 1977, 2000.

More generally, an I-fetchable concept may not have satisfiers even if the corresponding L-concept is locked onto some aspect of reality. Monadicization may yield a concept that is useful but importantly detached from reality. Note that (51) has an 'exhaustivity' implication:

(51) Plum lifted a piano

Plum was the lifter - and not merely $a$ lifter - in one or more events that satisfy 'lifted a piano'; cp. Carlson, 1984. Capturing this implication is easy, so long as one grants that (52): 
(52) The school faces the church

likewise implies a facing whose sole facer is the school. But suppose the school and church face each other, with (52) and (53) as equally good descriptions of the scene; cp. Schein, 1993, 2001, 2002.

(53) The church faces the school

Then there is a distinct facing whose sole facer is the church. If the school abuts the church, there are at least two abuttings; and so on. But it is hard to believe that the meanings of I-expressions populate the world in this way.

Various responses to such examples are possible. One might eschew the offending variables, even if this leaves no viable compositional theories of meaning for I-languages; cp. Fodor, 2003. In my view, this is overreaction, perhaps due to the following assumptions: theories of meaning for I-languages need to be theories of truth; and theories of truth will not traffic in variables whose values are so fine-grained. More constructively, one might posit logical forms with two 'tiers' of variables, one of which is heavily language-dependent; see e.g. Schein, 2002, forthcoming. There can be multiple perspectives on a scene. So one might speculate that I-expressions are used to build concepts as in (52a).

$$
\begin{aligned}
& \text { - }[\operatorname{SCENe}(\mathrm{S}), \exists \bullet[\operatorname{PERSPECTIVE}(\mathrm{S}, \mathrm{P}) \text {, }
\end{aligned}
$$

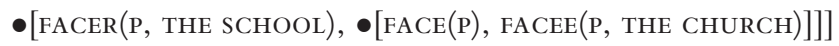

This is not what most advocates of Truth Conditional Semantics have in mind; cp. Russell's (1912) appeal to epistemically distant entities we can triangulate on via representations with which we are better acquainted. It is not clear that the world includes scenes that bear the right relations to perspectives, much less that our judgments are regularly of the following form: there is a scene on which there is a $\Phi$-ish perspective. Nor is it easy to see how such judgments could be formed simply by executing the semantic instructions issued by expressions plausibly generated by HFL. The requisite assumptions about lexicalization and composition, syntactic and semantic, are nontrivial. But Schein offers extensive evidence that the process of understanding expressions like (52-53) somehow involves perspectival variables that do not have events (in any ordinary sense) as values. One need not conclude, however, that such variables have values and appear in the judgments we make via expressions like (52-53). Lexicalizing a relational concept like FACE(X, y) may introduce a monadic concept, FACE(E), that does not have satisfiers but can be used to make concepts that are less perspectival.

Once an I-expression has been used to construct a sentential concept, S, S may be available as a representation we can think with. But there is no guarantee that $\mathrm{S}$ has a compositionally determined truth condition. And while there may be an associated representation, $S^{\star}$, that does have a truth condition, $S^{\star}$ may have been formed by taking $S$ as an input to further processing. Not all our thoughts need to be truth-evaluable. Often, we can reflectively form judgments that we can evaluate as true or false in contexts that theorists can control. This is a great source of 
evidence, much like our capacity to pause and make acceptability judgments. But if such judgments are interaction effects that reflect considerable post-SEM processing (cp. Hauser et al., 2002), theorists need not assume that every time we execute a declarative sentential SEM, the result is true or false.

\subsection{Intelligent Abstraction versus Lowest Common Denominators}

In this context, let me compare the kind of creative lexicalization proposed here with the kind envisioned by Frege (1884). On the one hand, there is nothing new in the idea that humans can use available concepts and a language to define formally distinct concepts that have attractive computational properties not exhibited by the initial concepts. Frege (1879) thought of his Begriffsschrift (Concept-Script), the basis for modern logic, in just this way; see Horty, 2007. But Frege assumed a classical conception of natural thought and grammar-according to which human concepts/predicates are massively monadic, as in syllogistic logic — and showed how to construct a more ideal language of thought, with atomic singular and relational concepts, governed by a powerful logic that permits introduction of higher-order concept. By contrast, my suggestion is that HFL doesn't support logically powerful abstraction or sophisticated inferences. Rather, HFL lets us use natural concepts (many of which are nonmonadic) to introduce and systematically combine massively monadic concepts that serve as 'common denominators' for our L-concepts. This kind of conceptual reformatting, which permits a lot of elementary conjunction, yields concepts governed by a less interesting logic.

Frege was especially interested in concepts that figure in proofs by induction. Such proofs can establish that there are infinitely many primes, given the axioms of arithmetic, or reduce these axioms to a more compact representation of any nonlogical basis for arithmetic. And Frege showed that arithmetic induction is a special case of logical induction applied to entities of a special sort. He defined the numbers so that for any property $\Phi$ : if (i) zero has $\Phi$, and (ii) if any given number has $\Phi$, so does its successor, then (iii) every number has $\Phi$. But this requires more than a logically unstructured monadic concept of numbers as objects.

Formally, NUmber(x) is like COw(x). Yet replacing 'number' with 'cow' in (ii) and (iii) does not preserve the compellingness of the inference. So Frege introduced a relational concept, NUMBER-OF[X, C(Y)], that applies to certain object-concept pairs. For example, 0 is the number of (things that fall under) the concept $\sim[=(\mathrm{Y}$, $\mathrm{Y})]$ - a.k.a. the concept NONSELFIDENTICAL $(\mathrm{Y}) ; 1$ is the number of the concept $=(0$, $\mathrm{Y}) ; 2$ is the number of $\mathrm{OR}[=(0, \mathrm{Y}),(1, \mathrm{Y})]$; etc. Frege also defined a higher-order concept, ANCESTRAL $[\mathrm{R}(\mathrm{X}, \mathrm{Y})]$, that can be saturated by a first-order relational concept like PREDECESSOR $(\mathrm{X}, \mathrm{Y})$ to yield a concept like PRECEDES $(\mathrm{X}, \mathrm{Y})$ whose extension is the transitive closure of the first. The idea is that for any relation: if $\mathrm{R}(\alpha, \beta)$ and $\mathrm{R}(\beta, \gamma)$, then ANCESTRAL $[\mathrm{R}(\mathrm{x}, \mathrm{y})](\alpha, \gamma)$; and similarly for any 'chain of $\mathrm{R}$-links'. Given these concepts, one can formulate the biconditional (54): $\mathrm{z}$ is a number iff 0 is or is an ancestral predecessor of $\mathrm{z}$. 
(54)

$$
\operatorname{Number}(\mathrm{z}) \equiv \mathrm{Or}\{=(0, \mathrm{z}), \operatorname{ANCESTRaL}[\operatorname{PredeCESSOR}(\mathrm{x}, \mathrm{y})](0, \mathrm{z})\}
$$

Whether (54) counts as analytic depends in part on whether one allows for analysis by abstraction, as opposed to decomposition; see Horty, 2007. But the suggestion is not that we naturally think about numbers via mental analogs of the right hand side of (54). Rather, (54) reflects Frege's attempt to say what numbers are-and how we can think of them-in a way that reflects our capacity to appreciate the validity of certain inductive inferences. In this sense, his Begriffsschrift is a language in which we can conduct recognizably human thought. But acquiring the relevant concepts requires intellectual work. Of course, we must entertain a thought-e.g. that every number is the predecessor of another - in order to analyze it. But we can use concepts like NUMBER(X) and PredeCESSOR(X, Y) to introduce technical analogs, with the aim of re-presenting our initial thought contents in ways that let us describe more inferences as formally valid. We can use (54) to replace NUMBER(z) with a more structured concept, when this is useful in a proof, and go back to $\operatorname{NUMBER}(z)$ when the further structure is irrelevant.

In two respects, I think the introduction of I-concepts is similar: such concepts have later birthdates than their L-concept analogs; and I-concepts are introduced because they can be manipulated by certain operations that cannot apply directly to L-concepts. But the point of using $\operatorname{KICK}(\mathrm{X}, \mathrm{Y})$ and thematic concepts to introduce $\operatorname{KICK}(\mathrm{E})$ is not to say what it is for a pair of individuals to satisfy $\operatorname{KICK}(\mathrm{X}, \mathrm{Y})$. Lexicalization is not metaphysics. The cognitive value of a Conjunctivist I-language is that it permits recursive combination of monadic I-concepts via simple operations that make conjunction-reduction the paradigmatic form of valid inference for these concepts. By contrast, the point of Fregean analyses is to get beyond this simple form of inference and highlight logical relations that hold among higher-order relational concepts. The inferential relation between $\operatorname{NUMBER}(\mathrm{x})$ and $\bullet[\operatorname{PRIME}(\mathrm{x})$, Number(x)] is obvious. Frege wanted to get at relations among number(x), Zero, $\operatorname{PREDECESSOR}(\mathrm{X}, \mathrm{Y})$, and ANCESTRAL[R(X, $\mathrm{Y})]$.

With regard to the domain of arithmetic, there is no prayer of getting at how things really are in a massively monadic system, or by restricting oneself to concepts that humans naturally acquire. I see no reason for thinking that arithmetic is special in this regard. On the contrary, it seems extremely unlikely that sentential expressions of a Conjunctivist I-language are used to construct judgments that have the truth conditions we actually endorse via these expressions. If this is correct, one can look for an another conception of lexicalization and composition that is still constrained enough to explain the facts that motivate Conjunctivist analyses, yet permissive enough to allow for a more transparent mapping from I-expression meanings to the truth conditions of constructable judgments. Alternatively, one might conclude that the gap between meaning and truth is nontrivial, given that lexicalization and semantic composition are severely constrained. In which case, the hard work will take the form of saying how meaningful I-expressions can be used to build concepts that are inputs to a more complex process of building concepts that we can use to make truth-evaluable judgments. I have been urging the second path. 


\section{Final Remarks}

Let me conclude by rehearsing the main line of thought. Natural languages, as objects of study, are possible states of HFL: biologically implementable generative procedures that pair PHONs with SEMs; where lexical SEMs are instructions to fetch concepts, and phrasal SEMs are instructions to execute constituent SEMs and combine the resulting concepts via certain operations that HFL can invoke. Many empirical considerations suggest that the concepts fetched are massively monadic, and that the constructed concepts are conjunctive. But since lexicalized concepts are often nonmonadic, we use these L-concepts to create a stock of I-concepts that can be conjoined with others, perhaps with the help of some thematic concepts whose participant variables can be existentially closed. These bleached I-concepts are poor candidates for being elements of a mental language for which a plausible theory of truth can be given. But they can provide a basis - perhaps necessary for creatures like us - for refinements and elaborations that can, with some luck, yield truth-evaluable judgments. Constructing sentences that can be true or false requires cognitive work, not just an exercise of our natural capacity to generate SEMs. But correlatively, the study of meaning can be a branch of inquiry that reveals important truths about human nature, without demeaning truth or exaggerating human nature.

\section{Departments of Linguistics and Philosophy University of Maryland}

\section{References}

Austin, J. 1962: How to do Things with Words. Oxford: Clarendon Press.

Bach, K. 1994: Conversational impliciture. Mind \& Language, 9, 124-62.

Baker, M. 1988: Incorporation. Chicago: University of Chicago.

Baker, M. 1997: Thematic roles and grammatical categories. In L. Haegeman (ed.), Elements of Grammar. Dordrecht: Kluwer, pp. 73-137.

Baker, M. 2003: Verbs, Nouns, and Adjectives. Cambridge: Cambridge University Press. Boolos, G. 1998: Logic, Logic, and Logic. Cambridge, MA: Harvard University Press.

Borer, H. 2005: Structuring Sense, vols I and II. Oxford: Oxford University Press.

Burge, T. 1973: Reference and proper names. Journal of Philosophy, 70, 425-39.

Carlson, G. 1984: Thematic roles and their role in semantic interpretation. Linguistics, 22, 259-79.

Carston, R. 2002: Thoughts and Utterances. Oxford: Blackwell.

Carston, R. 2008: Linguistic communication and the semantics pragmatics distinction. Synthese, 165, 15-44.

Carruthers, P. 2002: The cognitive functions of language. Behavioral and Brain Sciences, $25,657-74$. 
Castañeda, H. 1967: Comments. In N. Rescher (ed.), The Logic of Decision and Action. Pittsburgh, PA: Pittsburgh University Press.

Chierchia, G. 1998: Reference to kinds. Natural Language Semantics, 6, 339-405.

Chomsky, N. 1977: Essays on Form and Interpretation. New York: North Holland.

Chomsky, N. 1986: Knowledge of Language. New York: Praeger.

Chomsky, N. 1995: The Minimalist Program. Cambridge, MA: MIT Press.

Chomsky, N. 2000: New Horizons in the Study of Language and Mind. Cambridge: Cambridge University Press.

Crain, S. and Pietroski, P. 2001: Nature, nurture, and universal grammar. Linguistics and Philosophy, 24, 139-86.

Church, A. 1941: The Calculus of Lambda Conversion. Princeton, NJ: Princeton University Press.

Davidson, D. 1967a: The logical form of action sentences. In N. Rescher (ed.), The Logic of Decision and Action. Pittsburgh, PA: Pittsburgh University Press.

Davidson, D. 1967b: Truth and meaning. Synthese, 17, 304-23.

Dowty, D. 1979: Word Meaning and Montague Grammar. Boston: Reidel.

Dowty, D. 1991: Thematic proto-roles and argument selection. Language, 67, 547-619.

Dummett, M. 1975: What is a theory of meaning? In S. Guttenplan (ed.), Mind and Language. Oxford: Oxford University Press.

Elbourne, P. 2005: Situations and Individuals. Cambridge, MA: MIT.

Evans, G. 1982: Varieties of Reference. Oxford: Oxford University Press.

Fara, D. G. 2000: Shifting sands: an interest-relative theory of vagueness. Philosophical Topics, 28, 45-81. Originally published under the name 'Delia Graff'.

Fodor, J. 1975: The Language of Thought. New York: Crowell.

Fodor, J. 1986: Psychosemantics. Cambridge, MA: MIT Press.

Fodor, J. 2003: Hume Variations. Oxford: Oxford University Press.

Fodor, J. and Lepore, E. 2002: The Compositionality Papers. Oxford: Oxford University Press.

Fodor, J. and Pylyshyn, Z. 1988: Connectionism and cognitive architecture. Cognition, 28, 3-71.

Frege, G. 1879: Begriffsschrift. Halle: Louis Nebert. English translation in J.van Heijenoort (ed.), From Frege to Gödel: A Source Book in Mathematical Logic, 1879-1931. Cambridge, MA: Harvard University Press, 1967.

Frege, G. 1884: Die Grundlagen der Arithmetik. Breslau: Wilhelm Koebner. English translation in J. L. Austin (trans.), The Foundations of Arithmetic. Oxford: Basil Blackwell, 1974.

Frege, G. 1892 [1980]: Function and concept. In P. Geach and M. Black (ed. and trans.), Translations from the Philosophical Writings of Gottlob Frege. Oxford: Blackwell.

Frege, G. 1918 [1956]: The thought: a logical inquiry. Mind, 65, 289-311.

Gallistel, C. 1990: The Organization of Learning. Cambridge, MA: MIT Press. 
Giannakidou, A. and Stavrou, M. 1999: Nominalization and ellipsis in the Greek DP. The Linguistic Review, 16, 295-332.

Gillon, B. 1987: Readings of plural noun phrases in English. Linguistics and Philosophy, 102,199-219.

Hale, K. and Keyser, J. 1993: On argument structure and the lexical expression of syntactic relations. In K. Hale and J. Keyser (eds), The View from Building 20. Cambridge, MA: MIT Press.

Harley, H. 2006: The morphology of nominalizations and the syntax of $\mathrm{vP}$. In A. Giannakidou and A. Rathert (eds), Quantification, Definiteness, and Nominalization. Oxford: Oxford University Press.

Hauser, M., Chomsky, N., and Fitch, T. 2002: The faculty of language: what is it, who has it, and how did it evolve? Science, 298, 1569-79.

Heim, I. and Kratzer, A. 1998: Semantics in Generative Grammar. Oxford: Blackwell.

Higginbotham, J. 1983: The logical form of perceptual reports. Journal of Philosophy, 80, $100-27$.

Higginbotham, J. 1985: On semantics. Linguistic Inquiry, 16, 547-93.

Hornstein, N. and Pietroski, P. 2009: Basic operations: minimal syntax-semantics. Catalan Journal of Linguistics, 8, 113-39.

Horty, J. 2007: Frege on Definitions: A Case Study of Semantic Content. Oxford: Oxford University Press.

Hurford, J. 2007: The Origins of Meaning. Oxford: Oxford University Press.

Horwich, P. 1998: Meaning. Oxford: Oxford University Press.

Jackendoff, R. 1990: Semantic Structures. Cambridge, MA: MIT Press.

Jackendoff, R. 2002: Foundations of Language. Oxford: Oxford University Press.

Jacobson, P. 1999: Variable free semantics. Linguistics and Philosophy, 22, 117-84.

Kamp, H. 1975: Two theories about adjectives. In E. Keenan (ed.), Formal Semantics of

Natural Languages. Cambridge: Cambridge University Press.

Katz, J. and Fodor, J. 1963: The structure of a semantic theory. Language, 39, 170-210.

Katz, J. 1994: Names without bearers. Philosophical Review, 103, 1-39.

Kennedy, C. 1999: Gradable adjectives denote measure functions, not partial functions. Studies in the Linguistic Sciences, 29, 65-80.

Kratzer, A. 1996: Severing the external argument from its verb. In J. Rooryck and L. Zaring (eds), Phrase Structure and the Lexicon. Dordrecht: Kluwer Academic Publishers.

Kripke, S. 1979: Speaker's reference and semantic reference. Midwest Studies in Philosophy, 2, 255-76.

Larson, R. 1988: On the double object construction. Linguistic Inquiry, 19, 335-91.

Larson, R. Forthcoming: On Shell Structure. New York: Routledge.

Larson, R. and Segal, G. 1995: Knowledge of Meaning. Cambridge, MA: MIT Press. 
Levin, B. and Rappaport, M. 1995: Unaccusativity: At the Syntax-Semantics Interface. Cambridge, MA: MIT Press.

Levin, B. and Rappaport Hovav, M. 2005: Argument Realization. Cambridge: Cambridge University Press.

Lewis, D. 1972: General semantics. In D. Davidson and G. Harman (eds), Semantics of Natural Language. Dordrecht: Reidel.

Link, G. 1983: The logical analysis of plurals and mass terms: a lattice-theoretic approach. In R. Bäuerle, C. Schwarze and A. von Stechow (eds), Meaning, Use, and Interpretation of Language. Berlin: deGruyter.

Longobardi, G. 1994: Reference and proper names, Linguistic Inquiry, 25, 609-65.

Marantz, A. 1984: On the Nature of Grammatical Relations. Cambridge, MA: MIT Press.

Marr, D. 1982: Vision. San Francisco: Freeman and Company.

May, R. 1985: Logical Form: Its Structure and Derivation. Cambridge, MA: MIT Press.

McGilvray, J. 1998: Meanings are syntactically individuated and found in the head. Mind E Language, 13, 225-80.

McGilvray, J. 1999: Chomsky: Language, Mind and Politics. Cambridge: Polity Press.

Montague, R. 1974: Formal Philosophy. New Haven, CT: Yale University Press.

Matushansky, O. 2006: Why rose is the rose: on the use of definite articles in names. Empirical Issues in Syntax and Semantics, 6, 285-307.

Parsons, T. 1970: Some problems concerning the logic of grammatical modifiers. Synthese, 21, 320-34.

Parsons, T. 1990: Events in the Semantics of English. Cambridge, MA: MIT Press.

Pietroski, P. 2000: The Undeflated Domain of Semantics. Sats: Nordic Journal of Philosophy, 1, 161-76.

Pietroski, P. 2005a: Events and Semantic Architecture. Oxford: Oxford University Press.

Pietroski, P. 2005b: Meaning before truth. In G. Preyer and G. Peter (eds), Contextualism in Philosophy. Oxford: Oxford University Press.

Pietroski, P. 2006a: Interpreting concatenation and concatenates. Philosophical Issues, 16, $221-45$.

Pietroski, P. 2006b: Induction and comparison. Maryland Working Papers in Linguistics, 15, 157-90.

Pietroski, P. 2008: Minimalist meaning, internalist interpretation. Biolinguistics, 4, 317-41.

Pietroski, P. forthcoming a: Minimal semantic instructions. In C. Boeckx (ed.), The Oxford Handbook of Linguistic Minimalism. Oxford: Oxford University Press.

Pietroski, P. forthcoming b: Lexicalizing and Combining.

Pietroski, P., Lidz, J., Hunter, T. and Halberda, J. 2009: The meaning of 'most': semantics, numerosity, and psychology. Mind \& Language, 24, 554-85.

Putnam, H. 1975. The meaning of 'meaning'. In K. Gunderson (ed.), Language, Mind and Knowledge. Minneapolis, MN: University of Minnesota Press.

(C) 2010 Blackwell Publishing Ltd 
Ramchand, G. 2008: Verb meaning and the lexicon: a first phase syntax. Cambridge: Cambridge University Press.

Recanati, F. 2004: Literal Meaning. Cambridge: Cambridge University Press.

Rey, G. 2009: Concepts, defaults, and asymmetric dependencies. In N. Kompa, C. Nimtz, and C. Suhm (eds), The A Priori and Its Role in Philosophy. Paderborn: Mentis.

Russell, B. 1912: The Problems of Philosophy. London: Butterworth.

Quine, W. 1963: On what there is. In From a Logical Point of View. New York: Harper and Row.

Sainsbury, M. 1996: Concepts without Boundaries. In R. Keefe and P. Smith (eds), Vagueness: A Reader. Cambridge MA: MIT Press.

Schein, B. 1993: Plurals. Cambridge, MA: MIT Press.

Schein, B. 2001: Adverbial, descriptive reciprocals. In R. Hastings, B. Jackson and Z. Zvolenszky (eds), Proceedings of Semantics and Linguistic Theory XI. Ithaca, NY: CLC Publications.

Schein, B. 2002: Events and the semantic content of thematic relations. In G. Preyer and G. Peter (eds), Logical Form and Language. Oxford: Oxford University Press.

Schein, B. forthcoming: Conjunction Reduction Redux. Cambridge, MA: MIT Press.

Schwartzschild, R. 1996: Pluralities. Dordecht: Kluwer.

Segal, G. 2001: Two theories of names. Mind \& Language, 5, 547-63.

Spelke, E. 2002: Developing knowledge of space: core systems and new combinations. In S. Kosslyn and A. Galaburda (eds), Languages of the Brain. Cambridge, MA: Harvard University Press.

Stainton, R. 2006: Meaning and reference-some Chomskyan themes. In E. Lepore and B. Smith (eds), Handbook of Philosophy of Language. Oxford: Oxford University Press.

Stalnaker, R. 1984: Inquiry. Cambridge, MA: MIT Press.

Stanley, J. 2000: Context and logical form. Linguistics and Philosophy, 23, 391-424.

Stanley, J. 2002: Making it articulated. Mind \& Language, 17, 149-68.

Strawson, P. 1950: On Referring. Mind, 59, 320-44.

Svenonius, P. forthcoming: Spatial P in English. In G. Cinque and L. Rizzi (eds), The Cartography of Syntactic Structures, vol. 6. Oxford: Oxford University Press.

Szabó, Z. 2000: Compositionality as supervenience. Linguistics and Philosophy, 23, 475-505.

Tarski, A. 1933: The concept of truth in formalized languages. Reprinted in Logic, Semantics, Metamathematics $2^{\text {nd }}$ edn., trans. J. H. Woodger, ed. J. Corcoran. Indianapolis, IN: Hackett.

Taylor, B. 1985: Modes of Occurrence. Oxford: Blackwell.

Travis, C. 1985: On what is strictly speaking true. Canadian Journal of Philosophy, 15, 187-229. 
Travis, C. 1996: Meaning's role in truth. Mind, 105, 451-66.

Williams, A. 2007: Patients in Igbo and Mandarin. In J. Dölling and T. Heye-Zybatow (eds), Event Structures in Linguistic Form and Interpretation. Berlin: Mouton de Gruyter.

Williams, A. 2009: Themes, cumulativity, and resultatives. Linguistic Inquiry, 40, 686-700.

Wittgenstein, L. 1953: Philosophical Investigations. New York: Macmillan. 